\title{
Adapting to an Emerging Social Media Landscape: The Rise of Informalization of Company Communication in Tourism
}

\author{
Corné Dijkmans ${ }^{1(\bowtie)}$, Peter Kerkhof ${ }^{2}$, and Camiel Beukeboom ${ }^{2}$ \\ ${ }^{1}$ Breda University of Applied Sciences, Breda, The Netherlands \\ dijkmans. c@buas.nl \\ ${ }^{2}$ Vrije Universiteit Amsterdam, Amsterdam, The Netherlands
}

\begin{abstract}
This study investigates the evolvement of informalization of company communication on social media over time, based on actual social media data from the tourism industry. The development in the use of emoticons and emoji by companies is examined, as an expression of informalization and humanization of online company communication. We selected 33 companies from the tourism industry in The Netherlands and investigated their Facebook and Twitter messages supplemented with the messages of consumers who interacted with these companies, for the period 2011-2016. Results show that the use of emoticons and emoji in online company communication increased significantly over the period covered in this study, demonstrating a higher level of informalization of company communication. Since this is a key factor for improving relational outcomes, this finding has scholarly as well as managerial relevance. We discuss the implications of the results for the presence of organizations on social media.
\end{abstract}

Keywords: Social media $\cdot$ Conversational human voice $\cdot$ Informalization of communication $\cdot$ Textual paralanguage $\cdot$ Emoticons $\cdot$ Emoji

\section{Introduction}

Through social media, the world wide web has developed into a social environment, where people can interact, share ideas and generate content [1]. Consumers can easily connect with other consumers but also with organizations, brands and companies. As a result, for companies, customer involvement and engagement through social media have become an important factor in their marketing approach [2]. Social media platforms, such as Facebook and Twitter, offer companies various ways to communicate and interact with customers, to provide online customer service and product assistance, and to obtain feedback [3]. Several studies indicate that social media use by companies is beneficial if utilized correctly (e.g., [4]).

In the early days of social media, however, it was by no means evident that company social media use would be successful. Consumers were reluctant to companies intervening in their activities on social media. In a 2011 study, Heller Baird and Parasnis [5] argue that most consumers (70\%) mainly wanted to connect with friends and family on social media, while only $23 \%$ wanted to interact with companies and 
brands. Fournier and Avery [6] argue that companies were viewed with suspicion on social media, and their presence was easily perceived as intrusive. Companies were seen as "uninvited crashers of the Web 2.0 party" [6] (p. 192).

At the same time, it became increasingly important to establish a successful social media presence to engage with online consumers [7]. Traditional one-way company communication strategies were losing trust in favor of more conversational communication approaches. As a result, for companies, to (re)gain this trust, interactivity in online communication started to play a more important role. Interactivity has been defined as "the degree to which two or more communication parties can act on each other, on the communication medium, and on the messages and the degree to which such influences are synchronized" [8] (p. 54). Company interactivity in online communication reinforces consumer trust, satisfaction, and commitment [9], and consumer trust declines if consumers' expectations with regard to interactivity are not met [10].

To optimize consumers' level of perceived interactivity of a company, cognitive as well as affective cues must be present in communication [11]. Since computermediated communication may - through its mainly text-based orientation - more easily facilitate the cognitive aspects of communication, it poses challenges for companies with respect to its affective aspects. That is, communication via social media platforms lacks the ability of conveying nonverbal cues (e.g., facial expressions, tone of voice, physical touch, gestures, appearance) that are important for a correct mutual understanding and to pursue interpersonal goals $[12,20]$. The absence of nonverbal cues negatively influences the quality of communication and may result in misinterpretations, and in a decreased feeling of humanness, connectedness and intimacy [14]. To compensate for these shortcomings in social media, people have developed ways to give substance to these important affective (i.e., emotional and social) aspects of communication. This can be realized by fine-tuning text and using the correct tone of voice in social media messages, but also by the use of emoticons and emoji [15]. An emoticon is defined as "a group of keyboard characters (such as :-)) that typically represents a facial expression or suggests an attitude or emotion and that is used especially in computerized communications (such as e-mail)" [16]. Emoji are small pictograms of facial features, animals, and objects (e.g., or (-)). Emoticons and emoji intend to elucidate and fortify the meaning of messages between sender and receiver [12] and have become a popular means to improve the understanding of messages that was previously absent in online communication [17].

In conclusion, for companies to be successful on social media, properly dealing with the constraints of the medium (i.e., the difficulty to provide emotional and 'humane' cues as a result of its predominant text-based character) is of great importance. Remarkably, while social media have become increasingly important in company communication [18], there is a lack of research based on real-life data to describe and explain how companies have dealt with this challenge of computer-mediated communication with consumers as described above. This study tries to fill this gap by investigating actual real-life company social media data, and by examining how the use of emoticons and emoji has developed as an indication of the level of informalization and humanization of online company communication. 


\section{Theoretical Background}

Once company-consumer connections on social media became more common, consumers started to use companies' social media channels to ask questions, vent their complaints, give compliments, and share their ideas. Consequently, delivering customer service became a new part of company social media activities: webcare - often provided by designated teams/employees - emerged as a service and brand communication tool. Webcare was defined by Van Noort and Willemsen [3] as "the act of engaging in online interactions with (complaining) consumers, by actively searching the web to address consumer feedback (e.g., questions, concerns and complaints)" (p. 133). Several studies have emphasized the importance of providing proper webcare for companies [3, 19, 20]. Since webcare takes place in public and has to deal with (dis) satisfied customers, closely watched by bystanders, within short response times, it sets high requirements for company communication (e.g., [4]). Several studies show that to be successful in delivering webcare, using a personal voice that is relationship oriented (i.e., being authentic, 'human'), conversational capabilities and prompt responsiveness are important factors [9, 21-24].

These requirements of online company presence relate to the concept of conversational human voice (CHV), defined by Kelleher [9] as "an engaging and natural style of organizational communication as perceived by an organization's publics based on interactions between individuals in the organization and individuals in publics." (p. 177). Through this style of communicating, companies try to mimic face-to-face communication and to informalize and 'humanize' the corporate voice [25]. Within computer-mediated settings, applying a CHV by companies has proven to have positive effects on relational outcomes, such as trust, stakeholder involvement, and corporate reputation [3, 14, 19, 21, 26, 27]. In conclusion, successful company presence on social media depends strongly on successful interactions, and previous research shows that $\mathrm{CHV}$ is a crucial factor in accomplishing these fruitful interactions.

Applying a CHV in computer-mediated communication can be put into practice through the use of human representatives (i.e., webcare employees), informal language use, use of personal pronouns and - since nonverbal cues are lacking in online communication - textual paralanguage, defined by Luangrath et al. [13] as "written manifestations of nonverbal audible, tactile, and visual elements that supplement or replace written language and that can be expressed through words, symbols, images, punctuation, demarcations, or any combination of these elements." (p. 98). Important forms of such textual paralanguage are emoticons and emoji, which can be used to convey meaning and emotion to online textual communication [13], and thus contribute substantially to perception of CHV. The word 'emoticon' is a contraction of 'emotion' and 'icon'. Originally, emoticons were merely composed of regular keyboard characters, but as of October 2010, graphical emoticons (i.e., emoji) have been introduced and added to Unicode, the computing industry standard for encoding, representation, and handling of text, expressed in most of the world's writing and input systems. An emoji is a small graphical symbol, ideogram, or icon used to express an idea or emotion, and is originating from the Japanese words for picture ('e') and letter/character ('moji'). Authorities on language use have acknowledged emoji; for instance, The Oxford 
Dictionaries chose the 'face with tears of joy' emoji as Word of the Year in 2015 [28]. Since 2010, emoji are also included on default keyboards of mobile devices and have become very popular worldwide. For example, Instagram (an online mobile photo and video sharing platform) reported in March 2015 that nearly half of the texts on their platform contained emoji [29].

All these reports suggest that emoticons and emoji are now an undeniable part of the world's electronic communication vocabulary. They offer a range of sentiment and feelings that portray specific emotions through facial gestures, but also concepts and ideas, such as celebration, weather, vehicles and buildings, food and drink, animals and plants, and activities. Use of emoticons and emoji increases information richness, which plays an important role in facilitating social connectedness and identity expressiveness between users [30], and may thus drive intimacy, trust and commitment. Lo [15] found that the use of emoticons improved the level of understanding of messages in an online context, and emoticon us positively influenced the level and direction of emotion and attitude. The expression of emotions in online communications by the use of emoticons was found to be similar to the expression of emotions in face-to-face communication [31].

In sum, emoticons and emoji have proved to add value to computer-mediated interactions between individuals. However, to our knowledge, research to date has not yet investigated the use of emoticons and emoji by companies, and the developments therein. Given the relevance of non-verbal cues for successful online and interactive communication, and the lack of insights from actual practice in this field, in this study we will therefore investigate the development of emoticon and emoji use in real-life company communication. This results in our research question: how has the use of emoticons and emoji in social media communication of companies developed over time?

\section{Methodology}

For this study, we selected 33 large companies from the Dutch tourism Top 50 [32] with an active presence on Facebook as well as on Twitter. The remaining 17 companies from the Dutch tourism Top 50 had no active presence on social media (i.e., on Facebook and Twitter).

In order to answer our research question (i.e., how the use of emoticons and emoji in social media communication of companies has developed over time), we focused on the number and types of company social media messages over a six-year period, ranging from 2011 to 2016. In our study, we included all Facebook and Twitter messages of the selected Dutch tourism and travel companies. Facebook and Twitter are the two most commonly used online platforms for company-consumer communication and webcare; worldwide as well as in The Netherlands [33]. In 2017, Facebook is used by $94 \%$ of the companies using social media and Twitter by $68 \%$ [18]. In order to best capture interactivity and the two-way flow of information, we not only included the companies' messages, but also the messages of consumers that interacted with these companies. To investigate our research question, we content analyzed the companies' 
Facebook and Twitter messages from 2011 to 2016 on the presence of emoticons and/or emoji.

Our data were collected by performing a data mining exercise with the use of Coosto, a Dutch online social media monitoring platform [34]. The infrastructure provided by Coosto monitors online channels in 150 languages and in 200 countries [35]. With regard to The Netherlands, Coosto covers over 3 billion public social media messages, posted since 2009. Around 2.5 million new messages are added to its database per day. Messages can be selected and exported from the database with a query language and a web interface.

The overall profile of the number of social media messages created in general showed that, as to be expected, from the end of 2010 onwards an increasing number of messages were generated in The Netherlands. Therefore, we used January 2011 as the starting point for our study, and December 2016 as the end date, covering six years in total.

\subsection{Measures}

Posts and Reactions. We determined whether social media messages are either posts or reactions. In Coosto, a message is categorized as a post if the message is not preceded by an earlier message in the same conversation. In conversations, a post is always the opening message (i.e., the first message in a 'message thread'). A reaction is a response to a post or to another reaction (i.e., the second and further messages in a 'message thread'). For both posts and reactions, we distinguish between company and consumer messages. Company messages consist of all posts and reactions sent by the selected 33 tourism companies during the time period under investigation in this study (2011-2016). Consumer messages consist of posts and reactions addressed at the company channels included in our study (i.e., for Twitter: message contained a reference - i.e., an @ mention - to one of the selected companies; for Facebook: message was posted on one of the selected companies' Facebook pages). References to the 33 companies in messages not posted on the selected companies' social media channels were not included in this study (i.e., messages mentioning the company name or brand on Facebook/Twitter other than on the channels of the selected companies).

Emoji and Emoticons. To investigate the development of emoticons/emoji in the social media messages, the full content of all messages of the tourism companies on their Twitter and Facebook accounts was downloaded with a time stamp ranging from 2011 to the end of 2016. Additionally, we also downloaded the full content of the consumer posts and reactions connecting to the Twitter account of the 33 companies. Content of the consumer posts/reactions on the Facebook channels of the selected tourism companies (over 1.7 million messages) was not included in the analyses, because all full content downloads had to be performed in small batches of 10,000 (as a result of constraints by the Coosto software), making the total message volume too large for download.

In total, the content of 772,884 messages was downloaded (i.e., for Twitter: company as well as consumer posts and reactions; for Facebook: only company posts and 
reactions). Since we were interested in changes of the occurrence of emoji and emoticons, duplicate messages were removed (based on the URL and the content of the message) in order to avoid counts based on the occurrence of emoji and emoticons in the same reposted or retweeted message. After deduplication, 201,890 messages were removed, resulting in a final dataset of 570,994 messages. Table 1 shows the number of messages for the different categories.

Table 1. Volume of messages used for content analysis (total $N=570,994$ ). (compiled by authors)

\begin{tabular}{l|l|l|r|c}
\hline \multirow{2}{*}{} & \multicolumn{2}{l|}{ Facebook } & \multicolumn{2}{l}{ Twitter } \\
\cline { 2 - 5 } & Posts & Reactions & \multicolumn{1}{l}{ Posts } & Reactions \\
\hline Tourism companies & 37,111 & 71,759 & 63,372 & 99,290 \\
\hline Consumers & - & - & 134,993 & 164,469 \\
\hline
\end{tabular}

A list of 33 often used emoticons (e.g., :-), ;-)) was retrieved from the Github website [36] and used to scan the messages. Some infrequently occurring emoticons resulted in errors and were removed from the list (such as : c and :-*), resulting in a list of 22 emoticons. In order to code emoji, we retrieved an emoji dictionary from the Github website [37], containing 2,378 emoji and their UTF8 codes. From this script, we removed the part of the UTF8 code that referred to variations in skin tone of the 'people' emoji, thus reducing the list to 1,111 emoji. Using an R script, all 570,994 remaining company and consumer social media messages after deduplication were scanned on the occurrence of emoji and emoticons included on the final list, and categorized in 3 groups (i.e., messages containing emoticons, containing emoji, and messages without emoticons/emoji). Finally, we calculated the proportion of company messages with emoticons/emoji in the total number of messages.

\section{Results}

Scanning the 570,994 messages for emoji and emoticons resulted in 551 different emoji and 22 different emoticons. For each message, only unique occurrences of emoji and emoticons were counted, thus resulting in a score indicating the number of unique emoticons rather than the total number of emoji and emoticons. The 271,532 messages by tourism companies contained a total of 3,524 emoji and 41,277 emoticons; $0.9 \%$ of all messages contained one or more emoji, whereas $14.9 \%$ contained one or more emoticon. Table 2 gives a global summary of the emoji and emoticon proportions per year, showing a growth in emoticon and emoji use by companies in posts, and in particular in reactions. 
Table 2. Proportion of tourism company messages containing emoticons and emoji. (compiled by authors)

\begin{tabular}{l|l|l|l|l}
\hline \multirow{2}{*}{} & \multicolumn{3}{|l|}{ Facebook } & Twitter \\
\cline { 2 - 5 } & Company posts & Company reactions & Company posts & Company reactions \\
\hline 2011 & $2,2 \%$ & $12,3 \%$ & $3,0 \%$ & $11,9 \%$ \\
\hline 2012 & $2,9 \%$ & $10,1 \%$ & $3,1 \%$ & $13,4 \%$ \\
\hline 2013 & $4,6 \%$ & $17,3 \%$ & $2,3 \%$ & $13,3 \%$ \\
\hline 2014 & $8,6 \%$ & $28,5 \%$ & $3,1 \%$ & $14,7 \%$ \\
\hline 2015 & $10,5 \%$ & $51,8 \%$ & $3,5 \%$ & $23,7 \%$ \\
\hline 2016 & $16,3 \%$ & $47,9 \%$ & $4,9 \%$ & $26,7 \%$ \\
\hline Total & $9,1 \%$ & $41,7 \%$ & $3,1 \%$ & $19,6 \%$ \\
\hline
\end{tabular}

The 299,462 consumer messages contained 19,350 emoji and 25,142 emoticons; $5.1 \%$ of all consumer messages contained one or more emoji, whereas $8.3 \%$ contained one or more emoticons.

Tables 3 and 4 (see below) show the most frequently used emoticons and emoji by tourism companies and consumers. Interestingly, all of the top 10 emoticons used by consumers are also used by companies (see Table 3 below). The top 4 emoticons, which comprise of $95.3 \%$ of all emoticons used by companies and $86.8 \%$ of those used by consumers, are all of the 'smiling face' type. Only $2.0 \%$ of the emoticons used by companies are negative/sad emoticons, versus $7.0 \%$ among consumers.

Table 3. Top 10 of emoticons used by tourism companies and consumers, as a percentage of the total number of messages containing emoticons. (compiled by authors)

\begin{tabular}{l|l|l|l}
\hline \multicolumn{2}{l|}{ Companies } & \multicolumn{2}{l}{ Consumers } \\
\hline Emoticon & $\%$ of total & Emoticon & $\%$ of total \\
\hline$:)$ & $34.4 \%$ & $:)$ & $28.7 \%$ \\
\hline$:-)$ & $27.5 \%$ & $:-)$ & $27.5 \%$ \\
\hline$;)$ & $19.0 \%$ & $;-)$ & $17.3 \%$ \\
\hline$;-)$ & $14.4 \%$ & $;)$ & $13.3 \%$ \\
\hline$: \mathrm{D}$ & $1.9 \%$ & $:($ & $4.0 \%$ \\
\hline$:-($ & $1.1 \%$ & $: \mathrm{D}$ & $3.3 \%$ \\
\hline$:($ & $0.9 \%$ & $:-($ & $2.9 \%$ \\
\hline$:-\mathrm{D}$ & $0.4 \%$ & $<3$ & $1.0 \%$ \\
\hline$<3$ & $0.3 \%$ & $:-\mathrm{D}$ & $0.9 \%$ \\
\hline$=)$ & $0.1 \%$ & $=)$ & $0.3 \%$ \\
\hline Total & $99.2 \%$ & Total & $97.0 \%$ \\
\hline
\end{tabular}

The use of emoji is more varied (see Table 4 below), with the top 10 of emoji accounting for only half of all emoji used. Half of the top 10 emoji used by tourism companies are also in the top 10 of emoji used by consumers. All emoji that refer to 
human emotions are positive. Tourism companies more often use emoji that refer less directly to human emotions (e.g., a sun, an airplane, a palm tree).

Table 4. Top 10 of emoji used by tourism companies and consumers, as a percentage of the total number of messages containing emoji. (compiled by authors)

\begin{tabular}{|c|c|c|c|c|c|}
\hline \multicolumn{3}{|c|}{ Companies } & \multicolumn{3}{|c|}{ Consumers } \\
\hline UTF8 & emoji & $\%$ & UTF8 & emoji & $\%$ \\
\hline e2 9880 & ; & $11.9 \%$ & fo $9 f 918 d$ & 目 & $9.6 \%$ \\
\hline f0 9f 9889 & $\Leftrightarrow$ & $8.7 \%$ & f0 9f 9889 & (1) & $9.3 \%$ \\
\hline fo $9 \mathrm{f} 988 \mathrm{a}$ & (2) & $8.0 \%$ & f0 $9 \mathrm{f} 98 \mathrm{8a}$ & (2) & $7.1 \%$ \\
\hline fo $9 \mathrm{f} 8 \mathrm{c} \mathrm{b} 4$ & 留 & $4.1 \%$ & fo 9 f 9882 & (2) & $5.2 \%$ \\
\hline e2 9c 88 & $\downarrow$ & $3.5 \%$ & fo 9 f 9883 & (:) & $4.0 \%$ \\
\hline $\mathrm{c} 2 \mathrm{ae}$ & ® & $3.3 \%$ & f0 9f 9884 & $\Leftrightarrow$ & $3.7 \%$ \\
\hline f0 9f 9884 & $\Leftrightarrow$ & $3.1 \%$ & e2 98 ba & (i) & $2.8 \%$ \\
\hline fo 9 f 8 e 89 & 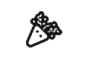 & $3.0 \%$ & f0 9f 9881 & (2) & $2.8 \%$ \\
\hline fo $9 f 918 d$ & 目 & $2.3 \%$ & e2 9880 & $*$ & $2.6 \%$ \\
\hline fo $9 \mathrm{f} 988 \mathrm{~d}$ & 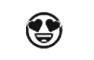 & $2.2 \%$ & f0 9f 9880 & :) & $2.5 \%$ \\
\hline Total & & $50.1 \%$ & Total & & $49.6 \%$ \\
\hline
\end{tabular}

Subsequently, we investigated the trends in emoticon/emoji use by companies. To this end we performed Mann-Kendall (M-K) trend tests on the emoticon/emoji proportions on a per week basis for the 6 years included in this study. The M-K test is a commonly used nonparametric test for identifying a trend in series, resulting in the M$\mathrm{K}$ statistic $(S)$ per time series. The purpose of the M-K test is to statistically assess if there is a monotonic upward or downward trend in a variable over time. Except for company Twitter posts $(S=8833$, Kendall's $\tau=.18$, n.s. $)$, this analysis indeed revealed significant increases $(p<.001)$ in emoticon/emoji use in company communication for the years 2011-2016 (Twitter reactions: $S=22409$, Kendall's $\tau=.46$; Facebook posts: $S=30806$, Kendall's $\tau=.63$; Facebook reactions: $S=27710$, Kendall's $\tau=.57$ ).

\section{Conclusion and Discussion}

The advent of social media has presented major opportunities and challenges for traditional business communication strategies. Consumers can effortlessly share their thoughts about companies and services anywhere, anytime and to anyone. Companies 
want to participate in this online consumer communication [18], and have invested in online strategies and webcare teams to directly connect with consumers, for delivering customer service [38], protecting reputation [4], enhancing brand popularity [5], and improving company trust $[39,40]$.

However, little research has investigated trends in volume and type of company social media communication based on actual data, from a macro perspective. To fill this gap, in this study we provided empirical evidence of the increase of informalization and humanization of company communication as indicated by the use of emoticons and emoji. This is an important finding: since vital cues that normally regulate interactions and impressions between communicators are absent in online social interaction (e.g., someone's voice or facial expression, observable information about personal and physical characteristics) [26], companies are looking for ways to overcome this shortage, for instance by incorporating emoticons and emoji in their messages. The use of emoticons has proven to have a positive effect on enjoyment, personal interaction, and perceived information richness [41]. By using emoticons and emoji, we argue that companies contribute to their perceived level of conversational human voice (CHV), which has proven to be an important mechanism for effective company communication in social media [9, 29]. First, incorporating a more humanized voice makes consumers sense they are having a one-to-one conversation instead of a one-to-many conversation, which in turn contributes to a better relationship with customers [38, 42]. Second, by using a $\mathrm{CHV}$, the company seems to focus on creating a dialogue rather than solely on commercial and profit-driven motives, which makes the company appear more authentic in its intentions [25]. Thirdly, companies can be perceived as more trustworthy when they use a more human tone of voice [43]. In sum, by adding informal cues such as emoticons to their online communication, company-consumer relations may be evaluated more easily as interpersonal relationships by consumers. This builds on the concept of parasocial interaction [44], stating that the impact of (online) communications depends on the degree to which the counterparty in a computer mediated communication environment is perceived as a real person [45].

Another finding was that the use of emoticons and emoji by companies and consumers shows remarkable similarities. The top 10 of used emoticons and half of the top 10 of emoji are identical among companies and consumers. Although the repertoire of emoticons/emoji is limited, this equality is nevertheless striking. This may be the result of social synchrony in online social media: "the tendency of a large group of people to perform similar actions in unison, in response to a contextual trigger" [46] (p. 151). Mimicry of the nonverbal cues and tone of voice of an online communication partner may contribute to the feeling of connectedness in online interactions, and thus may improve relational outcomes.

Several limitations of this study should be noted. First, social media monitoring tools such as Coosto only give access to public social media messages; therefore we were not able to include private messages between companies and consumers in this study. This may have affected the quantity or quality of messages and/or the use of emoticons. Second, we focused on Facebook and Twitter in this study. Although these two platforms are by far the largest for company-consumer interaction [18], additional perspectives of including other platforms may have been missed. Third, since this study is limited to the tourism industry and more specifically to The Netherlands, the findings 
may not be representative for all industries or countries. Fourth, although the use of emoticons and emoji are important clues for the level of informalization of company communication, other indicators (such as the use of informal and colloquial language, degree of openness to dialogue, promptness of feedback) may yield important additional perspectives. In order to more fully investigate the developments in these fields, future research may include a broader range of measures for humanization of communication. This may be part of a broader research avenue on the role of emotions in corporate communication. That is, emotions are abundant in online communication and key factors for its success [47], but their role and effects are - to our knowledge - not profoundly studied in a setting of online company-consumers interactions.

Despite these limitations, this study contributes to a better understanding of the development of informalization of online company communication over the last years. In this study we have shown that over recent years, companies have enhanced their sense of informality and humanness in online conversations. By learning step by step how to engage with consumers in an environment that was initially created for peopleto-people interaction, tourism companies that appropriately utilize the power of social media and the connected consumer are well on their way to evolve from 'party crashers' to 'party hosts'.

\section{References}

1. Kaplan AM, Haenlein M (2010) Users of the world, unite! The challenges and opportunities of Social Media. Bus Horiz 53:59-68. https://doi.org/10.1016/j.bushor.2009.09.003

2. Harrigan P, Evers U, Miles M, Daly T (2017) Customer engagement with tourism social media brands. Tour Manag 59:597-609. https://doi.org/10.1016/j.tourman.2016.09.015

3. van Noort W (2012) Online damage control: the effects of proactive versus reactive webcare interventions in consumer-generated and brand-generated platforms. J Interact Mark 26:131140. https://doi.org/10.1016/j.intmar.2011.07.001

4. Dijkmans C, Kerkhof P, Beukeboom CJ (2015) A stage to engage: social media use and corporate reputation. Tour Manag 47:58-67. https://doi.org/10.1016/j.tourman.2014.09.005

5. Heller Baird C, Parasnis G (2011) From social media to social customer relationship management. Strategy Leadersh 39:30-37. https://doi.org/10.1108/10878571111161507

6. Fournier S, Avery J (2011) The uninvited brand. Bus Horiz 54:193-207. https://doi.org/10. 1016/j.bushor.2011.01.001

7. Rather RA, Hollebeek LD, Islam JU (2019) Tourism-based customer engagement: the construct, antecedents, and consequences. Serv Ind J 39:519-540. https://doi.org/10.1080/ 02642069.2019 .1570154

8. Liu Y, Shrum LJ (2002) What is interactivity and is it always such a good thing? Implications of definition, person, and situation for the influence of interactivity on advertising effectiveness. J Advert 31:53-64. https://doi.org/10.1080/00913367.2002. 10673685

9. Kelleher T (2009) Conversational voice, communicated commitment, and public relations outcomes in interactive online communication. J Commun 59:172-188. https://doi.org/10. 1111/j.1460-2466.2008.01410.x

10. Bauer HH, Grether M, Leach M (2002) Building customer relations over the internet. Ind Mark Manag 31:155-163. https://doi.org/10.1016/S0019-8501(01)00186-9 
11. Cui N, Wang T, Xu S (2010) The influence of social presence on consumers' perceptions of the interactivity of web sites. J Interact Advert 11:36-49. https://doi.org/10.1080/15252019. 2010.10722176

12. Derks D, Bos AER, von Grumbkow J (2008) Emoticons and online message interpretation. Soc Sci Comput Rev 26:379-388. https://doi.org/10.1177/0894439307311611

13. Luangrath AW, Peck J, Barger VA (2017) Textual paralanguage and its implications for marketing communications

14. Janssen JH, Ijsselsteijn WA, Westerink JH (2014) How affective technologies can influence intimate interactions and improve social connectedness. Int J Hum-Comput Stud 72:33-43. https://doi.org/10.1016/j.ijhcs.2013.09.007

15. Lo S-K (2008) The nonverbal communication functions of emoticons in computer-mediated communication. Cyberpsychol Behav 11:595-597. https://doi.org/10.1089/cpb.2007.0132

16. Merriam-Webster (2019) Definition of 'Emoticon'. https://www.merriam-webster.com/ dictionary/emoticon

17. Aldunate N, González-Ibáñez R (2017) An integrated review of emoticons in computermediated communication. Front Psychol 7:2061. https://doi.org/10.3389/fpsyg.2016.02061

18. Stelzner M (2017) Social media marketing industry report 2017. Social Media Examiner

19. Schamari J, Schaefers T (2015) Leaving the home turf: how brands can use webcare on consumer-generated platforms to increase positive consumer engagement. J Interact Mark 30:20-33. https://doi.org/10.1016/j.intmar.2014.12.001

20. Willemsen L, Neijens P, Bronner F (2013) Webcare as customer relationship and reputation management? Motives for negative electronic word of mouth and their effect on webcare receptiveness. In: Rosengren S, Dahlén M, Okazaki S (eds) Advances in Advertising Research. Springer, vol. IV, pp 55-69

21. Dijkmans C, Kerkhof P, Buyukcan-Tetik A, Beukeboom CJ (2015) Online conversation and corporate reputation: a two-wave longitudinal study on the effects of exposure to the social media activities of a highly interactive company. J Comput-Mediat Commun 20:632-648. https://doi.org/10.1111/jcc4.12132

22. Kent ML, Taylor M (1998) Building dialogic relationships through the world wide web. Public Relat Rev 24:321-334. https://doi.org/10.1016/S0363-8111(99)80143-X

23. Rybalko S, Seltzer T (2010) Dialogic communication in 140 characters or less: how fortune 500 companies engage stakeholders using Twitter. Public Relat Rev 36:336-341. https://doi. org/10.1016/j.pubrev.2010.08.004

24. Weinberg BD, Pehlivan E (2011) Social spending: managing the social media mix. Bus Horiz 54:275-282. https://doi.org/10.1016/j.bushor.2011.01.008

25. Kwon ES, Sung Y (2011) Follow me! Global marketers' Twitter use. J Interact Advert 12:416. https://doi.org/10.1080/15252019.2011.10722187

26. Beldad A, de Jong M, Steehouder M (2010) How shall I trust the faceless and the intangible? A literature review on the antecedents of online trust. Comput Hum Behav 26:857-869. https://doi.org/10.1016/j.chb.2010.03.013

27. Beukeboom CJ, Kerkhof P, de Vries M (2015) Does a virtual like cause actual liking? How following a brand's Facebook updates enhances brand evaluations and purchase intention. J Interact Mark 32:26-36. https://doi.org/10.1016/j.intmar.2015.09.003

28. Oxford Dictionaries (2015) Oxford dictionaries word of the year 2015 is.... In: OxfordWords Blog. https://blog.oxforddictionaries.com/2015/11/word-of-the-year-2015-emoji/

29. Dimson T (2015) Emojineering part 1: machine learning for emoji trends. In: Instagram Eng. https://engineering.instagram.com/emojineering-part-1-machine-learning-for-emoji-trendsmachine-learning-for-emoji-trends-7f5f9cb979ad 
30. Hsieh SH, Tseng TH (2017) Playfulness in mobile instant messaging: examining the influence of emoticons and text messaging on social interaction. Comput Hum Behav 69:405-414. https://doi.org/10.1016/j.chb.2016.12.052

31. Derks D, Bos AER, von Grumbkow J (2007) Emoticons and social interaction on the internet: the importance of social context. Comput Hum Behav 23:842-849. https://doi.org/ 10.1016/j.chb.2004.11.013

32. TravMagazine (2016) Travel Top 50

33. Chaffey D (2016) Global social media statistics summary 2016. In: Smart Insights. http:// www.smartinsights.com/social-media-marketing/social-media-strategy/new-global-socialmedia-research/

34. Coosto (2017) About Coosto. In: Coosto. https://www.coosto.com/en/about-us

35. Coosto (2015) Coosto facilitates worldwide social media analysis. In: Coosto. https://www. coosto.com/en/press/coosto-facilitates-worldwide-social-media-analysis

36. Malhotra E (2017) EmoticonSentiment: evaluating the relative sentiment attached to each emoticon

37. Suárez Colmenares F (2017) Emoji dictionary. In: GitHub. https://raw.githubusercontent. com/felipesua/sampleTexts/master/emojis.csv

38. van Noort G, Willemsen L, Kerkhof P, Verhoeven J (2014) Webcare as an integrative tool for customer care, reputation management, and online marketing: a literature review. In: Integrated communications in the postmodern era. Palgrave Macmillan, pp 77-99

39. Laroche M, Habibi MR, Richard M-O, Sankaranarayanan R (2012) The effects of social media based brand communities on brand community markers, value creation practices, brand trust and brand loyalty. Comput Hum Behav 28:1755-1767. https://doi.org/10.1016/j. chb.2012.04.016

40. Turri AM, Smith KH, Kemp E (2013) Developing affective brand commitment through social media. J Electron Commer Res 14:201-214

41. Huang AH, Yen DC, Zhang X (2008) Exploring the potential effects of emoticons. Inf Manage 45:466-473

42. Locke C, Searls D, Weinberger D, Levine R (2001) The cluetrain manifesto: the end of business as usual. Basic Books

43. Kelleher T, Miller BM (2006) Organizational blogs and the human voice: relational strategies and relational outcomes. J Comput-Mediat Commun 11:395-414. https://doi.org/ 10.1111/j.1083-6101.2006.00019.x

44. Horton D, Wohl RR (1956) Mass communication and para-social interaction: observations on intimacy at a distance. Psychiatry 19:215-229

45. Labrecque LI (2014) Fostering consumer-brand relationships in social media environments: the role of parasocial interaction. J Interact Mark 28:134-148. https://doi.org/10.1016/j. intmar.2013.12.003

46. Choudhury MD, Sundaram H, John A, Seligmann DD (2009) Social synchrony: predicting mimicry of user actions in online social media. In: 2009 International conference on computational science and engineering. pp 151-158

47. Derks D, Fischer AH, Bos AER (2008) The role of emotion in computer-mediated communication: a review. Comput Hum Behav 24:766-785. https://doi.org/10.1016/j.chb.2007. 04.004 
30. Hsieh SH, Tseng TH (2017) Playfulness in mobile instant messaging: examining the influence of emoticons and text messaging on social interaction. Comput Hum Behav 69:405-414. https://doi.org/10.1016/j.chb.2016.12.052

31. Derks D, Bos AER, von Grumbkow J (2007) Emoticons and social interaction on the internet: the importance of social context. Comput Hum Behav 23:842-849. https://doi.org/ 10.1016/j.chb.2004.11.013

32. TravMagazine (2016) Travel Top 50

33. Chaffey D (2016) Global social media statistics summary 2016. In: Smart Insights. http:// www.smartinsights.com/social-media-marketing/social-media-strategy/new-global-socialmedia-research/

34. Coosto (2017) About Coosto. In: Coosto. https://www.coosto.com/en/about-us

35. Coosto (2015) Coosto facilitates worldwide social media analysis. In: Coosto. https://www. coosto.com/en/press/coosto-facilitates-worldwide-social-media-analysis

36. Malhotra E (2017) EmoticonSentiment: evaluating the relative sentiment attached to each emoticon

37. Suárez Colmenares F (2017) Emoji dictionary. In: GitHub. https://raw.githubusercontent. com/felipesua/sampleTexts/master/emojis.csv

38. van Noort G, Willemsen L, Kerkhof P, Verhoeven J (2014) Webcare as an integrative tool for customer care, reputation management, and online marketing: a literature review. In: Integrated communications in the postmodern era. Palgrave Macmillan, pp 77-99

39. Laroche M, Habibi MR, Richard M-O, Sankaranarayanan R (2012) The effects of social media based brand communities on brand community markers, value creation practices, brand trust and brand loyalty. Comput Hum Behav 28:1755-1767. https://doi.org/10.1016/j. chb.2012.04.016

40. Turri AM, Smith KH, Kemp E (2013) Developing affective brand commitment through social media. J Electron Commer Res 14:201-214

41. Huang AH, Yen DC, Zhang X (2008) Exploring the potential effects of emoticons. Inf Manage 45:466-473

42. Locke C, Searls D, Weinberger D, Levine R (2001) The cluetrain manifesto: the end of business as usual. Basic Books

43. Kelleher T, Miller BM (2006) Organizational blogs and the human voice: relational strategies and relational outcomes. J Comput-Mediat Commun 11:395-414. https://doi.org/ 10.1111/j.1083-6101.2006.00019.x

44. Horton D, Wohl RR (1956) Mass communication and para-social interaction: observations on intimacy at a distance. Psychiatry 19:215-229

45. Labrecque LI (2014) Fostering consumer-brand relationships in social media environments: the role of parasocial interaction. J Interact Mark 28:134-148. https://doi.org/10.1016/j. intmar.2013.12.003

46. Choudhury MD, Sundaram H, John A, Seligmann DD (2009) Social synchrony: predicting mimicry of user actions in online social media. In: 2009 International conference on computational science and engineering. pp 151-158

47. Derks D, Fischer AH, Bos AER (2008) The role of emotion in computer-mediated communication: a review. Comput Hum Behav 24:766-785. https://doi.org/10.1016/j.chb.2007. 04.004 